\title{
Month-of-the-Year and Symmetrical Effects in the Nikkei 225
}

\author{
Ricky Chee-Jiun Chia ${ }^{1}$, Venus Khim-Sen Liew ${ }^{2}$ \\ ${ }^{1}$ Labuan School of International Business and Finance, Universiti Malaysia Sabah, Malaysia \\ ${ }^{2}$ Faculty of Economics and Business, Universiti Malaysia Sarawak, Malaysia
}

\begin{abstract}
This study finds significant November effect in the Nikkei 225 index of the Tokyo Stock Exchange (TSE). This finding is consistent with previous evidence supportive of tax-loss selling hypothesis for the stock markets of U.S. and U.K. In addition, the estimated Threshold generalized autoregressive conditional heteroscedasticity (TGARCH) model reveals no significant asymmetrical effect on good and bad news. The existence of month-of-the-year effect in TSE suggests that by means of properly timed investment strategies, financial managers, financial counselors and investors could take advantage of the patterns and gain profit.
\end{abstract}

Keywords: month-of-the-year-effect, Nikkei 225, TGARCH

\section{Introduction}

Understanding the stock market behavior especially the price movement and the return generating mechanism is always of great interest to not only the market participants, but also academicians. In this regard, historical stock price has become the main tool for the academicians and non-academicians in studying and predicting the stock market movement or the performance of particular companies. Important information, among others, that can be abstracted from historical stock prices is the month-of-the-year effect.

Month-of-the-year effect is a form of calendar anomaly in which the mean return of a specific month is consistently different from those of other months. The most prevalent moth-of-the-year effect is the January effect, where returns are significantly higher than any other month (see Coutts et al., 2000 and the references therein). However, January is not always the month with the highest return in the literature ${ }^{1}$. Bhabra et al. (1999), Gibson et al. (2000) and Johnston and Paul (2005), for instance, reported November effect in some stock markets.

The existence of the month-of-the-year effect holds important implications for the markets and investors. If month-of-the-year effect existsed in stock returns, investors might be enable to take advantage of relatively regular patterns in the market by designing trading strategies, which accounts for such predictable patterns. As this nature of study has various important implications to stock market participants, there are abundant of studies attempting to search for calendar anomalies from the stock markets all over the world (See, Rozeff and Kinney, 1976; Gultekin and Gultekin, 1983; Lakonishok and Smidt, 1989; Balaban, 1995; Choudhry, 2001; Mehdian and Perry, 2002; Fountas and Segredakis, 2002).

In reviewing the related literature, few observations are remarkable. First, it is noticed that many of the studies on month-of-the-year effect were done in the selected Western developed markets, for example, Germany, U.S., and U.K. stock markets (Rozeff and Kinney, 1976; Gultekin and Gultekin, 1983; Lakonishok and Smidt, 1989; Choudhry, 2001; Mehdian and Perry, 2002). Less attention is paid to another developed market, namely the Japan stock market, which is also the largest stock market in Asia (Groenewold, Tang and $\mathrm{Wu}, 2004)^{2}$. The Tokyo Stock Exchange (TSE) located in Tokyo, Japan, is the second largest stock exchange market in the world by monetary volume. The TSE trading began on June 1, 1878 and functioned as the central market of Japan, thereby playing a crucial role in the growth and expansion of the nation's economy. The TSE had a market value of $¥ 559$ trillion as of the end of March 2007 and a trading value of $¥ 678$ trillion for the fiscal year ended March 31, 2007, making it one of the leading stock exchanges in the world in terms of size and liquidity ${ }^{3}$. Owing to the influential role it plays in the world markets, it is important to see if patterns of market

\footnotetext{
${ }^{1}$ See, among others, Arsad and Coutts (1997), Baker and Limmark (1998), Cheung and Coutts (1999), Bhabra et al. (1999), Coutts and Sheikh (2000) and Johnston and Paul (2005).

${ }^{2}$ Two exceptional studies on calendar anomalies for this market are Kato (1994) and Hamori (2001). Kato (1994) provided day of the week effect in the Japanese stock returns, whereas Hamori (2001) found monthly effects in various Japanese stock returns.

${ }^{3}$ Besides, the TSE currently lists 2,271 domestic companies and 31 foreign companies, with a total market capitalization of over 5 trillion USD. Stocks listed on the TSE are separated into the First Section (for large companies), the Second Section (for mid-sized companies), and the "Mothers" section (for high-growth startup companies). As of March 2006, there are 1,721 First Section companies, 489 Second Section companies and 156 Mothers companies. The TSE offers a wide range of exchange services. The main indices tracking the TSE
} 
returns existed in the market. Thus, this study attempts to examine if month-of-the-year effect is present in this Japan stock market ${ }^{4}$.

Second, according to Engle (1993), finding of certain patterns in volatility may be useful in several ways, including the use of predicted volatility patterns for hedging and speculative purposes and in valuation of certain assets specifically stock index option. For example, risk adverse investors may adjust their portfolio by reducing their investment in those assets whose volatility is expected to increase. Besides, it is important to know whether a high (low) return is associated with the corresponding high (low) return for a given day. This is because such knowledge may allow investors to adjust their investment portfolio by taking into account of the day-of-the-week variations in volatility. In this regard, few studies, like Choudhry (2001) and Holden et al. (2005) have employed the generalized autoregressive conditional heteroscedasticity (GARCH) models of Bollerslev (1986) to account for the time varying volatility of the stock returns in the month-of-the-year effect. According to Engle (2001), it is commonly observed that the negative returns are followed by a higher volatility than the positive returns. Engle and Ng (1993) also points out that the market reaction on bad and good news tends to be asymmetry in nature. Such asymmetric behaviour in stock returns could be identified using the Threshold GARCH (TGARCH) model (see, Zakoian, 1994 and Glosten et al.1993). Thus, more works are needed to study the month-of-the-year effect using asymmetric GARCH model for a better understanding of stock market behaviors.

Therefore, the purpose of this study is to examine the month-of-the-year effect and its volatility in Japan stock market by using the Nikkei 225 index. Once patterns of month-of-the-year effects are identified, it will give an opportunity to individual investors or investment firms to develop relevant profitable trading strategies to invest in this market. Besides, due to the limitation of the previous study, this study attempts to fill up the research gaps, by providing the evidence based on the result from the asymmetric GARCH model.

\section{Empirical Approach}

The following ordinary least squares (OLS) model with lagged return is employed to test for the month-of-the-year effect (Coutts et al., 2000) ${ }^{5}$ :

$$
R_{t}=\alpha_{0}+\sum_{i=1}^{11} \alpha_{i} M_{i t}+\theta_{1} R_{t-1}+\varepsilon_{t}
$$

where $R_{t}=100 \times \ln \left(I_{t} / I_{t-1}\right)$ denotes return at time $t$, where $\ln$ stands for logarithm, $I_{t}$ and $I_{t-1}$ are the values for Nikkei index for month $t$ and $t-1$ respectively. $M_{1 t}, M_{2 t}, \ldots, M_{11 t}$ are monthly dummy variables which corresponding to February, March, $\ldots$ and December respectively. The coefficient $\alpha_{0}$ measures the mean return for January, whilst the coefficients $\alpha_{1}$ through $\alpha_{11}$ represent the average differences in return between January and each individual month. The null hypothesis is no month-of-the-year effect ( $H_{0}: \alpha_{1}=, \ldots,=\alpha_{11}=0$ ). If the result is on the contrary (at least one $\alpha$ is not zero), then it could be concluded that the market index is characterized by statistically different average returns. Therefore, the rejection of the null hypothesis would imply that month-of-the-year effect is indeed present.

To take into account of time variation in the variance of stock returns and asymmetry behavior of the stock market, the following TGARCH model of autoregressive order $p$ and moving average order $q$ is estimated accordingly in this study:

$$
\sigma_{t}^{2}=\beta_{0}+\sum_{j=1}^{p} \gamma_{j} \sigma_{t-j}^{2}+\sum_{i=1}^{q} \beta_{i} \xi_{t-i}^{2}+\sum_{i=1}^{11} \alpha_{i} M_{i t}+\phi \xi_{t-1}^{2} N_{t-1}
$$

where $\sigma_{t}^{2}$ is the conditional variance of the residuals obtained from Equation (1). The dummy $N_{t-1}$ takes on value 1 when the stock index falls in the current period and 0 for increments of the stock index.

In this specification, $\phi$ is use to capture the asymmetrical effect of good news (increase in stock index) and bad news (decrease in stock index), as reflected by the differential effects on the conditional variance. In

are the Nikkei 225 index of companies selected by the Nihon Keizai Shimbun (Japan's largest business newspaper). See, Annual Report 2007, Tokyo Stock Exchange Group, INC.

${ }^{4}$ Hamori (2001) used analysis of variance approach to test whether the average return of each month is the same. Stock market volatility and asymmetric behavior are not considered in his study. The current study adopts the threshold generalized autoregressive conditional heteroscedasticity (TGARCH) model that to cater for these two important aspects that may affect the outcome of study.

${ }^{5}$ Note that the lagged return, $R_{t-1}$, is included here but not in Coutts et al. (2000) to eliminate serial correlation effect, see Kiymaz and Berument (2003). 
particular, good news has an impact of $\beta_{i}$, while bad news has an impact of $\left(\beta_{i}+\phi\right)$. Besides, if $\phi \neq 0$, the news impact is asymmetric which can be capture by the $t$-test of individual significance. Moreover, positive value of $\phi$ indicates the existence of a leverage effect in that bad news increases volatility. Note that, if the included monthly dummy variables are still significant in the mean equation, it may be concluded that the calendar effect is not due to the variation in the equity risk. Otherwise, the calendar effect can be explained by equity risk. Furthermore, if the monthly dummy variables are insignificant in the mean equation but significant in the variance equation, it can be concluded that there is calendar effect in market risk (Lucey, 2000).

\section{RESULTS AND DISCUSSION}

The data of this study consist of the monthly stock indices of the Japan stock market - Nikkei 225 over the period from January 2000 to June 2009. The preliminary OLS result as tabulated in Table 1 indicates that significant positive returns on November is observed in Japan, in accord with few previous studies (See, Bhabra et al., 1999; Gibson et al., 2000). The positive November month-of-the-year effect in Japan stock market could be due the tax-loss selling (Bhabra et al., 1999; Johnston and Paul, 2005). In contrast, the prevalent January effect as documented in majority of the literature is not observed in this Japan stock market. The monthly returns derived from the findings summarized in Table 1 are plotted in Figure 1.

Table 1: Ordinary Least Square (OLS) Results

\begin{tabular}{|c|c|}
\hline Parameter & Japan (Nikkei 225) \\
\hline Constant, $\alpha_{0}$ & $-3.1209(0.1216)$ \\
\hline February, $\alpha_{1}$ & $3.5698(0.2006)$ \\
\hline March, $\alpha_{2}$ & $4.0636(0.1430)$ \\
\hline April, $\alpha_{3}$ & $3.8964(0.1596)$ \\
\hline May, $\alpha_{4}$ & $2.6820(0.3318)$ \\
\hline Jun, $\alpha_{5}$ & $4.1273(0.1371)$ \\
\hline July, $\alpha_{6}$ & $-0.2535(0.9286)$ \\
\hline August, $\alpha_{7}$ & $4.0660(0.1576)$ \\
\hline September, $\alpha_{8}$ & $0.0894(0.9748)$ \\
\hline October, $\alpha_{9}$ & $0.0969(0.9729)$ \\
\hline November, $\alpha_{10}$ & $4.8150(0.0956)^{* * *}$ \\
\hline December, $\alpha_{11}$ & $4.1937(0.1403)$ \\
\hline Return (-1), $\vartheta_{1}$ & $0.2210(0.0252)^{* * *}$ \\
\hline \multicolumn{2}{|c|}{ ARCH-LM Statistic ( $p$-value) } \\
\hline 5 lags & 0.9192 \\
\hline 10 lags & 0.7799 \\
\hline \multicolumn{2}{|c|}{ Ljung-Box $Q^{2}$ Statistic ( $p$-value) } \\
\hline 5 lags & 0.9320 \\
\hline 10 lags & 0.7900 \\
\hline \multicolumn{2}{|c|}{ Wald Test ( $p$-value) } \\
\hline F-statistic & 0.4343 \\
\hline Chi-square & 0.4246 \\
\hline
\end{tabular}

Note: $* * *$ and $* * *$ denote significant at 1,5 and $10 \%$ level respectively. Numbers in parentheses depict p-value. The null hypothesis of the Wald Test is: $H_{0}: \alpha_{1}=\alpha_{2}=\ldots=\alpha_{10}=\alpha_{11}$ (same average monthly return for the year, implying no month-of-the-year effect).

\footnotetext{
${ }^{6}$ The most frequently cited explanation for the possible existence of a November effect (See, Johnston and Paul, 2005).
} 


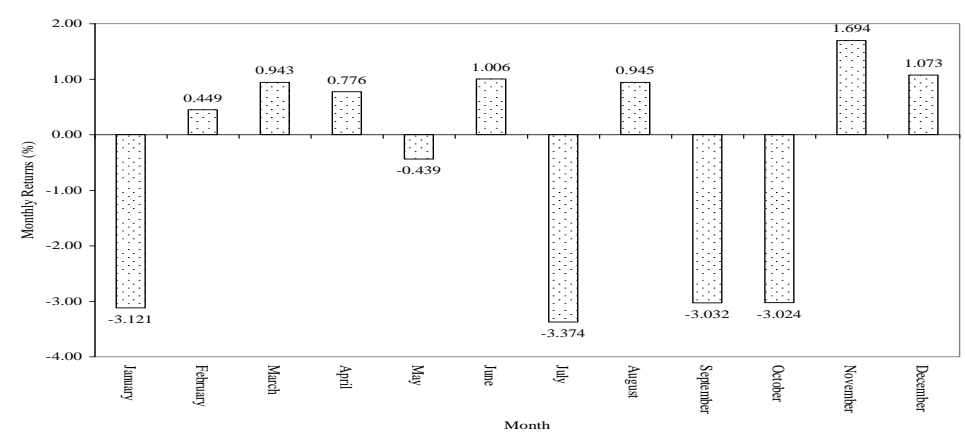

Fig. 1. Monthly Returns Estimated by OLS Model.

The estimated TGARCH model for the Japan stock market is presented in Table 2 below $^{7}$. TGARCH model of autoregressive order 1 and moving average order 1 , denoted as TGARCH $(1,1)$ model has been selected as optimum model. The estimated $\beta$ is significantly positive for Japan stock market. It implies that good news increase market volatility and therefore is compensated by higher returns. The estimated $\beta$ for the Japan is $0.7973 \%$, indicating that good news raise the volatility in returns by $0.7973 \%$ for the market (significant at $1 \%$ level). The leverage effect $(\phi)$ is estimated to be $0.2436 \%$. However, it is statistically insignificant, implying no asymmetry market response with respect to good and bad news. With respect to the month-of-the-year effect and stock market risk, the significant and positive returns for November as revealed in Table 1 before has now become insignificant in the mean equation. This suggests that the positive November returns found earlier could be due to equity risk.

Table 2: Estimated Threshold GARCH model

\begin{tabular}{|c|c|}
\hline Parameter & Japan (Nikkei 225) \\
\hline$(p, q)$ & $(1,1)$ \\
\hline Constant, $\alpha_{0}$ & $-0.4253(0.4453)$ \\
\hline November, $\alpha_{10}$ & $1.4929(0.3869)$ \\
\hline Return (-1), $\vartheta_{1}$ & $0.2390(0.0229)^{* *}$ \\
\hline \multicolumn{2}{|c|}{ Variance Equation } \\
\hline Constant & $4.0316(0.3707)$ \\
\hline$\gamma_{1}$ & $-0.0640(0.6633)$ \\
\hline$\beta_{1}$ & $0.7973(0.0000)^{* * * *}$ \\
\hline$\phi$ & $0.2436(0.1209)$ \\
\hline November, $\alpha_{10}$ & $2.6550(0.8562)$ \\
\hline \multicolumn{2}{|c|}{ ARCH-LM Statistic ( $p$-value) } \\
\hline 5 lags & 0.6993 \\
\hline 10 lags & 0.9064 \\
\hline \multicolumn{2}{|c|}{ Ljung-Box $\mathrm{Q}^{2}$ Statistic ( $p$-value) } \\
\hline 5 lags & 0.8460 \\
\hline 10 lags & 0.9070 \\
\hline \multicolumn{2}{|c|}{ Wald Test ( $p$-value) } \\
\hline F-statistic & 0.8566 \\
\hline Chi - square & 0.8562 \\
\hline
\end{tabular}

Notes: *,** and *** denote significant at 1,5 and $10 \%$ level respectively. Numbers in parentheses depict $p$-values. The null hypothesis of the Walt Test is $H_{0}: \alpha_{1}=\alpha_{2}=\ldots=\alpha_{11}$ (same average monthly return for the year, implying no monthof-the-year effect). The selection of appropriate orders of $p$ and $q$ in this study to be determined by Schwarz Information Criterion (SIC).

\footnotetext{
${ }^{7}$ Only the November dummy, which is significant by the preliminary OLS estimation, is included.
} 


\section{Concluding Remarks And Implications Of The Study}

The Japan stock market exhibits November effect over the period from January 2000 to June 2009. While the result is in extreme contrast to majority of previous international evidence that reported highest returns on January for both developed and emerging markets, it is nonetheless consistent with the findings of Bhabra et al. (1999), Gibson et al. (2000) and Johnston and Paul (2005). According to Bhabra et al. (1999) and Johnston and Paul (2005), the existence of November effect may be driven by the tax-loss selling behavior of individuals. Moreover, it is found from estimated the TGARCH model that the positive November returns are adequate to compensate individuals for the level of risk they assumed (Lucey, 2000). On the other hand, no asymmetrical effect on good and bad news was detected in this study. Hamori (2001) pointed out that the existence of seasonal effect implies the possibility of obtaining abnormal returns by means of properly timed investment strategies. Hence, the findings of November effect in this study could have important implications for financial managers, financial counselors and investors who intend to take advantage of the patterns and gain profit.

\section{Acknowledgement}

This research is partially supported by the research grant fund FRGS/05(16)/729/2010(15) granted by the Malaysian Higher Ministry of Education.

\section{References:}

[1.] Arsad, Z. and Coutts, A. (1997). Security price anomalies in the London International Stock Exchange, a sixty year perspective, Applied Financial Economics, 7, 455 - 464.

[2.] Balaban, E. (1995). January effect, yes! What about Mark Twain effects? The Central Bank of the Republic of Turkey: Discussion Paper No: 9509 .

[3.] Baker, R. and Limmack, R. J. (1998). Firm size, monthly seasonalities and tax-loss selling: further evidence from the UK, Bristish Accounting Review, 30, $221-248$.

[4.] Bhabra, H., Dhillon U. and Ramirez, R. (1999). A November Effect? Revisiting the Tax-Loss-Selling Hypothesis, Financial Management, 28, $5-15$

[5.] Bollerslev, T. 1986. Generalised Autoregressive Conditional Heteroscedasticity. Journal of Econometrics, 31: 307-327.

[6.] Cheung, K.C. and Coutts, J.A. (1999). The January effect and monthly seasonality in the Hang Seng index: 1985 - 97, Applied Economics Letters, 5, $121-123$.

[7.] Choudhry, T. (2001). Month of the year effect and January effect in Pre-WW1 stock returns: Evidence from a nonlinear GARCH model, International Journal of Finance and Economics, 6, 1-11.

[8.] Coutts, J.A. and Sheikh, M.A. (2000). The January effect and monthly seasonality in the All Gold Index on the Johannesburg Stock Exchange 1987 - 1997, Applied Economics Letters, 7, 489 - 492.

[9.] Coutts, J.A., Kaplanidisj, C. and Roberts, J. (2000). Security price anomalies in an emerging market: the case of the Athens Stock Exchange, Applied Financial Economics, 2000, 10, 561-571.

[10.] Engle, R. (1993). Statistical models for financial volatility, Financial Analysis Journal, 72 - 78

[11.] Engle, R. (2001). GARCH 101: The use of ARCH / GARCH models in Applied Econometrics, Journal of Economics Perspectives, $15,157-168$.

[12.] Engle, R.F. and Ng, V.K. (1993). Measuring and Testing the Impact of News on volatility, Journal of Finance, 48, $1749-1778$.

[13.] Fountas, S. and Segredakis, K. N. (2002). Emerging stock markets return seasonalities: the January effect and the tax-lo selling hypothesis, Applied Financial Economics, 12, 291 - 299

[14.] Gibson, S., Safieddine, A. and Titman, S. (2000). Tax motivated trading and price pressure: An analysis of mutual fund holding, Journal of Financial and Quantitative Analysis, 369 - 386.

[15.] Gultekin, M.N. and Gultekin, N.B. (1983). Stock market seasonality: International Evidence, Journal of Financial Economics, 12, $469-481$.

[16] Glosten, L. R., Jaganathan, R. \& Runkle, D. 1993. On The Relation between the Expected Value and the Volatility of the Normal Excess Return on Stocks. Journal of Finance. 48:1779 - 1801.

[17.] Groenewold, N., Tang, S. H. K. \& Wu. Y. 2004. The dynamic interrelationships between the greater China share markets. China Economic Review. 14: 45-62

[18.] Hamori, S. (2001). Seasonality and stock returns: some evidence from Japan, Japan and the World Economy, 13,463 - 481

[19.] Holden, K., Thompson, J. and Ruangrit, Y. (2005). The Asian crisis and calendar effects on stock returns in Thailand, European Journal of Operational Research, 163, $242-252$

[20..] Jang, H. and Sul, W. (2002). The Asian Financial Crisis and the Co-movement of Asian stock markets, Journal of Asian Economics, $13,94-104$.

[21.] Johnston, K. and Paul, C. (2005). Further evidence of the November effect, Journal of Economics and Finance, 29, 280 - 288.

[22.] Kato, K. (1990). Weekly Patterns in Japanese Stock Returns, Management Science, 36, 1031-1043

[23.] Kiymaz, H. and Berument, H. (2003). The day of the week effect on stock market volatility and volume: International evidence, Review of Financial Economics, 12, 363-380.

[24.] Lakonishok, J. and Smidt, S. (1989). Are seasonal anomalies real? A 90-year perspective, Review if Financial Studies, 1, 403 - 426

[25.] Lucey, B.M. (2000). Anomalous daily seasonality in Ireland? Applied Economics Letters, 7, 637 - 640.

[26.] Mehdian, S. and Perry, M. J. (2002). Anomalies in US equity markets: a re-examination of the January effect, Applied Financial Economics, 12, $141-145$.

[27.] Rozeff, M.S. and Kinney, W.R. (1976). Capital market seasonality: the case of stock returns, Journal of Financial Economics, 3 , $379-402$.

| [28.] Zakoian, J.M. (1994). Threshold heteroscedactic models, Journal of Economic Dynamics and Control, _-18, 931 - 944. 